DOI 10.1515/linpo-2016-0015

\title{
Selected semitransitive constructions in Algonquian
}

\author{
Fernando Zúñiga \\ Department of Linguistics, University of Bern \\ e-mail: fernando.zuniga@isw.unibe.ch
}

\begin{abstract}
Fernando Zúñiga. Selected semitransitive constructions in Algonquian. The Poznań Society for the Advancement of Arts and Sciences, PL ISSN 0079-4740, pp. 211-229

The present paper surveys a number of selected constructions in Algonquian languages that fall between those expressing transitivity and those expressing intransitivity (Hopper \& Thompson 1980; Dryer 2007). Socalled passives are mostly agentless and show different kinds of allomorphy in the particular languages. Antipassives are not fully understood yet but seem to be more idiosyncratic than passives, and are not found everywhere in the family. Lastly, systematic mismatches between morphological and syntactic valency (similar to constructions found in Oceanic and other languages) seem to play an important role in the inventory of constructions used to express less than full transitivity in Algonquian.
\end{abstract}

Keywords: Algonquian languages, passive, antipassive, transitivity discord, semitransitive

\section{Introduction}

\subsection{Semitransitivity}

Aside from Kleinschmidt's (1851) use of the term halbtransitiv 'semi-transitive' to refer to the Eskimoan antipassive, Sugita (1973) proposes using its English translation to refer to a particular class of verbs in some Oceanic languages. Benton (1967) labels the corresponding verb class in another Oceanic language "nontransitive" instead; Margetts (2008) uses the term "transitivity discord" in her brief survey of the clause/construction type involved and does not use Sugita's label for the class of verbs, which is actually heterogeneous - she distinguishes four distinct subclasses of such verbs in Saliba. ${ }^{1}$

${ }^{1}$ I do not address even less widespread uses of the relatively uncommon term SEMITRANSITIVE here, e.g. to refer to verbs like English have, which take direct objects but fail to passivize, or simply to experiencer verbs in different languages. 
The essentials of the phenomenon can be illustrated with the following example from Manam:

(1) Manam (West Oceanic, Papua New Guinea)
a. Bóro e u-rere-t-á'-di.
pig this 1SG.SBJ.REAL-like-THC-TR-3PL.OBJ
'I like these pigs.' (Margetts 2008: 34)
b. U-tán.
1SG.SBJ.REAL-cry
'I cried.' (Lichtenberk 1983: 28)
c. Deparóbu u-rerére.
rice 1sG.SBJ.REAL-like
'I like rice (in general).' (Margetts 2008: 34)

There is a formal opposition between default transitive clauses (a) and intransitive ones (b); the former have a transitive marker -á on the verb, absent from the latter. Some bivalent verbs, however, can also occur in a construction that resembles a transitive clause because there is an object but also resembles an intransitive clause because there is no transitive marker (c). Such verbs (and, by extension, the clauses they head) can be, and have been, called semitransitive.

A similar phenomenon is found in languages neither genealogically nor areally related to Oceanic, like Koryaboro Senni (2). In this language, there is a formal opposition between default transitive clauses (a) and intransitive ones (b); the former have an APV order and a transitivity marker $n a$, whereas the latter have an $\mathrm{SV}(\mathrm{X})$ order (where X represents an adjunct, or at least a non-object, marked with a postposition) and no transitivity marker. Semantically bivalent verbs like 'fear' (c) and 'see' (d), however, routinely occur in clauses that are somewhere in between: the NP corresponding to their P argument is postverbal (like adjuncts) but unmarked (like objects), and there is no transitivity marker. Such verbs (and, by extension, the clauses they head) can be, and have been, called semitransitive:

(2) Koryaboro Senni (Songhay, Mali)
a. A na ham yaa.
3SG TR meat eat
'He ate meat.' (Heath 1999: 165)
b. A koy koyr-aa ra.
$3 \mathrm{SG}$ go town-DEF LOC
'He went to the city.' (Heath 1999: 137)
c. Ay ga humbur hans-o.
$1 \mathrm{SG}$ INCOMPL fear dog-DEF
'I am afraid of the dog.' (Prost 1956: 124)
d. Ay di né wand-o.
$1 \mathrm{SG}$ see $2 \mathrm{SG}$ wife-DEF
'I saw your wife.' (Prost 1956: 87) 
Abstracting from the language-specific details, the notion as proposed by Sugita could be used to cover quite generally "clauses that $[. .$.$] behave in some ways like intransitive$ clauses, but in other ways like transitive clauses" (Dryer 2007: 262), referring essentially to constituent order, flagging, and indexing patterns. Note that such a broad definition leaves open whether the alternation between transitive and semitransitive clauses is determined grammatically (like in Manam and the Oceanic languages addressed by Sugita 1973, as well as in Yukulta, see Keen 1983) or lexically (like in Koryaboro Senni). Dryer (2007: 265) further states that

semi-transitive clauses are probably not a well-defined crosslinguistic category, in contrast to intransitive clauses and transitive clauses. [...] The label [...] indicates nothing more than the fact that the clauses so designated are problematic as far as the traditional distinction between intransitive and transitive clauses is concerned.

In the spirit of Dryer's (2007) suggestion and following Hopper \& Thompson's (1980) approach in distinguishing seeing intransitive and transitive clauses as polar opposites, I use the label SEMITRANSITIVE in the present article as an umbrella term for a whole array of constructions that fall in between the two poles with respect to semantic, morphological, and syntactic parameters. ${ }^{3}$ Consider the following transitivity cline:

\section{Cline of transitivity}

a. Intransitive clauses (that express "low semantic transitivity")

b. Semitransitive clauses (that express "intermediate semantic transitivity")

c. Transitive clauses (that express "high semantic transitivity")

This terminology makes the poles rather precise, at least in principle and language-specifically, viz. the two constructions used with Hopper \& Thompson's maximal cluster of low-transitivity and high-transitivity values, respectively. By contrast, the intermediate zone between the poles is quite broad. Kemmer's $(1993,1994)$ study of middle voice is similar in that it also features a fairly broad zone of constructions expressing what she calls "low degree of elaboration of events," which includes different subtypes of reflexives, reciprocals, passives, and her several middle subtypes, among others.

For our present purposes, suffice it to say here that syntactic and morphological valency may be at odds with the semantics of a given construction. At the low-transitivity pole, for instance, a valency of one may be seen everywhere (only one, subject, NP, and only one argument marked via affixes on the verb); analogously, at the high-transitivity pole, a valency of two may be seen in the syntax (subject and direct object NPs) and the morphology (subject and direct object affixes). Constructions expressing intermediate

${ }^{2}$ Hopper \& Thompson's parameters include kinesis, modality, aspectuality, and polarity in addition to number and kinds of participants, and there might be several constructions more or less specialized for different values, or combinations of values, of these parameters. Bear in mind that transitivity is crucially different from VALENCY here, which refers exclusively to the number of participants in the semantics, (predicate) morphology, or syntax.

${ }^{3}$ One of the reasons not to use DETRANSITIVE as umbrella term is that it is more specific, both etymologically and as found in most descriptive studies that use it: the detransitive construction (e.g. with a dedicated verb form as its head) is derived from the transitive one (the semitransitive may or may not be). 
transitivity values, by contrast, may have one or two core syntactic arguments (e.g. passives, antipassives, noun incorporation, etc.) and may have one or two arguments morphologically marked by the verb. Rather than exploring all the attested combinations, the present article maps some of the most prominent phenomena related to these issues as they are found in Algonquian languages.

\subsection{Transitivity in Algonquian}

The Algonquian languages of North America are among the well-studied linguistic families of the New World; as to their morphosyntax, they are especially noted by Americanists and typologists due to their obviation system (Aissen 1997) and the direct-inverse opposition in their verbal morphology and clause structure (Zúñiga 2006). The languages chosen here are among those with comparatively comprehensive grammatical descriptions particularly suited to the task at hand.

Of paramount importance for a proper understanding of the constructions that are at the center of attention in this article are the notions of finals and voice markers as used in Algonquian studies. The model of Algonquian verbal stems currently in use goes back to Bloomfield's work (e.g. Bloomfield 1946) and distinguishes three positions or slots in the stem structure: initial, medial, and final. Roughly, morphemes that occur in the initial position are verb roots. Those occurring in the medial position are nouns or suffixes many of which apparently originated as incorporated nouns - that express notions related to nominal properties and body parts. Morphemes occurring in the final position are derivational suffixes that specify in principle the transitivity/valency of the clause (I will come back to this crucial distinction in 1.3 below) and the animacy of the $\mathrm{S} / \mathrm{P}$ argument, and the many different finals establish a four-way classification of verbal stems: inanimate intransitive (II), animate intransitive (AI), transitive inanimate (TI), and transitive animate (TA). These final suffixes or finals are heterogeneous, however; some cannot be said to have much more semantics than the one related to transitivity and animacy, whereas others express qualifying notions like 'by hand', 'on foot', or the like. Well-formed stems can lack medials, but they must have at least one initial and one final. Derived verbs can apply the structural template recursively, thereby creating complex structures with, e.g., several finals ("primary and secondary derivation," see Goddard 1990). The following Blackfoot examples illustrate the initial oma'it- 'believe' taking three different finals to form stems, viz. AI -aki (a), TI -oo (b), and TA -o (c):

Blackfoot (Frantz 2009: 98)
a. oma'it-aki-
'believe' (animate intransitive)
b. oma'it-oo-
'believe (something)' (transitive inanimate)
c. oma'it-o-
'believe (somebody)' (transitive animate)

${ }^{4}$ Throughout this article, Frantz's spellings correspond to surface forms that may differ from the underlying representations given here, due to morphophonemic regularities; see Frantz (2009: 154f) for details. 
Algonquian studies customarily analyze some of these finals as voice markers. ${ }^{5}$ For Blackfoot, -ohsi and -(o)tsiiyi are the reflexive and the reciprocal marker, respectively, both of which turn TA stems into AI stems. The suffixes -átssi and -(o)mo are the default causative and the benefactive applicative marker, respectively; the former turns intransitive verbs into transitive verbs, and the latter can have either intransitive or transitive verbs as input. The following examples illustrate stems with these four voice markers:

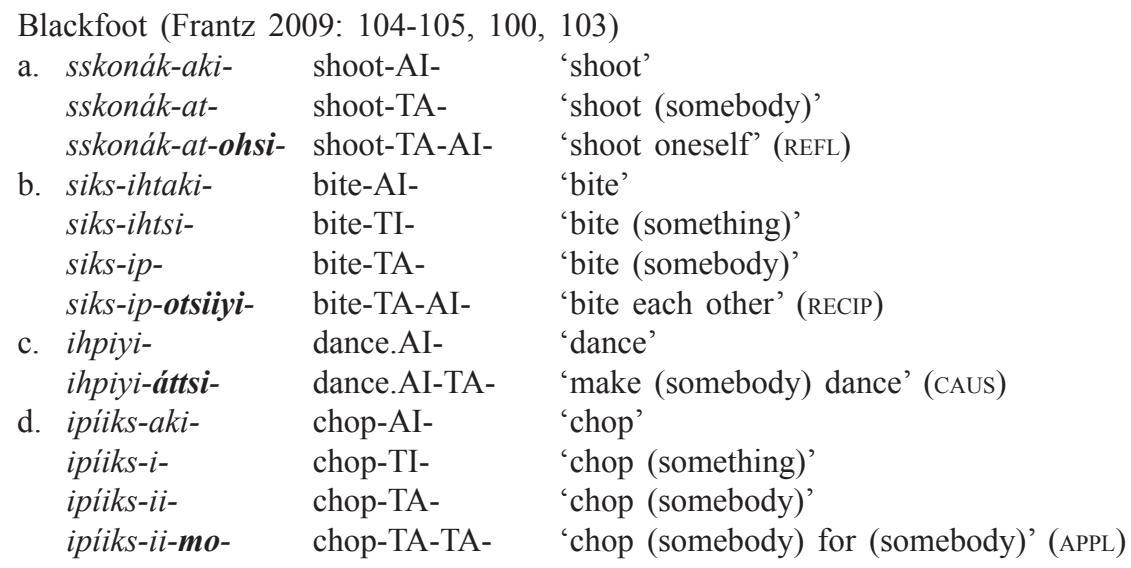

Finally, the finals determine the kind of inflection verb forms may take (6). The argument-related morphology of simple, i.e. non-secondarily derived, Blackfoot AI verbs, for example, consists of person and number markers corresponding to the subject (a). TI verbs mark their subject for person and number, their object for number only (it can only be the 3rd person), and take a person-sensitive direct "theme suffix" - zero with 1st- or 2nd-person (henceforth: speech act participants or SAPs) subjects, like here, and - $m$ with 3rd-person subjects - (b). Lastly, TA verbs mark their subject and their object, and take a theme suffix (here: direct $-a a$ ), as in (c).
Blackfoot (own field notes, cf. Frantz 2009: 40f, 145f)
a. nit-siks-ihtaki
1-bite-AI
'I bite'
nit-siks-ihtaki-hp-innaan
1-bite-AI-SAP-1PL.EXCL
b. nit-siks-ihtsi-hp-wa
1-bite-TI-SAP-3SG
'we (EXCL) bite'
nit-siks-ihtsi-hp-yi
1-bite-TI-SAP-3PL
'I bite it'
'I bite them (INAN)'

\author{
nit-siks-ihtsi-hp-innaan-wa \\ 1-bite-TI-SAP-1PL.EXCL-3SG \\ 'we (EXCL) bite it'
}

${ }^{5}$ Algonquian studies distinguish between abstract finals, which basically only determine the AI/II/TI/TA class of the verb, and concrete finals, which additionally contribute some semantic content to the whole; voice markers belong to the latter category.

${ }^{6}$ The most adequate synchronic morphemic treatment of some Algonquian finals in general, and of a number of Blackfoot finals in particular, is still a matter of debate. Here, the three finals -ihtaki AI, -ihtsi TI, and -ip TA stand in an opposition that is less than straightforward. They all contribute to the semantics of the verb stem ('with the mouth'), but the first two are probably further segmentable (i.e. they include a concrete element $i h t$ and the abstract finals that also occur elsewhere $-a k i$ and $-i$ ) while the latter one is not. Since this issue does not bear on the topics that are at the center of attention in the present paper, I have chosen not to over-segment finals here. 


$\begin{array}{lll}\text { c. } \text { nit-siks-ip-aa-wa } & \text { nit-siks-ip-aa-yi } & \text { nit-siks-ip-aa-nnaan-wa } \\ \text { 1-bite-TA-DIR-3SG } & \text { 1-bite-TA-DIR-3PL } & \text { 1-bite-TA-DIR-1PL.EXCL-3SG } \\ \text { 'I bite him' } & \text { 'I bite them (ANIM)' } & \text { 'we (EXCL) bite him' }\end{array}$

The inflectional affixes involved here are nit- '1', -(i)nnaan '1PL.EXCL', - wa '3sG', $-y i$ '3PL', $-a a$ 'DIRECT', and $-h p$ 'SPEECH-ACT PARTICIPANT'. Note that the latter marker occurs on TI verbs with singular or plural subjects and on AI verbs with plural subjects only; it never occurs on TA verbs. ${ }^{7}$

\subsection{Content and scope of the present article}

Algonquian AI verbs mark one argument - which is unsurprising if they are bona fide semantically intransitive and syntactically monovalent predicates - while TI and TA verbs mark two. The question that concerns us in the rest of the article is, to what extent does this morphological characterization of Algonquian predicate stems correlate with semantic transitivity and syntactic valency?

Part of the answer should be given before proceeding any further. On the one hand, there are systematic matches between particular verb forms and their use (e.g. with passives and antipassives, which are derived AI versions of TI/TA verb stems). On the other, there exist systematic mismatches as well, e.g. cases of AI stems appearing in clauses with an object and TI stems in clauses without an object. Against this background, I will present a survey of Algonquian passives and antipassives, in addition to what I will call, following Margetts's proposal for Oceanic, the transitivity discord construction (TDC). All of these constructions are seen here as special kinds of semitransitive constructions, but I will not address other semitransitive constructions that merit a separate study, e.g. reflexives, reciprocals, and nominal incorporation. ${ }^{8}$ Section 2 outlines the basics and some family- and language-internal variation of constructions that have been called "passives." Section 3 does the same, albeit more sketchily, for antipassives. Section 4 presents the several Algonquian transitivity discord constructions, and Section 5 concludes the article.

\section{Algonquian (so-called) passives}

In this paper, passives are treated as semitransitive constructions instead of simply intransitive ones because they normally have two/three semantic participants (although they do not have two/three core syntactic arguments) and are therefore of higher seman-

7 The exact meaning and behavior of $-w a$ and $-y i$ is more complicated than the glosses suggest. Both affixes index 3SG objects and 3PL objects, respectively, on TI and TA verbs, but with SAP subjects only. While the suffix $-y i$ indexes 3PL subjects on all classes of verbs (but surfaces only under special conditions with TA verbs), $-w a$ indexes only 3sG proximate subjects on all classes of verbs (3sG obviative subjects are indexed via -yini instead).

${ }^{8}$ Another area I gloss over in the present article is the role played by ditransitives (i.e. trivalent TA verbs). 
tic transitivity than a bona fide one-participant clause. Note that I provide neither new evidence nor new thoughts regarding whether some or most of so-called passives in Algonquian are best seen as bona fide passives or as indefinite-actor constructions (see below); I use the term "passive" merely as shorthand here.

With the exception of some constructions found in Arapaho (see below), Algonquian passives appear to be quite homogeneous with respect to their basic characterization, especially regarding their syntax. Individual-language descriptions invariably portray such constructions not only as possibly promoting the argument in P function to subject status but also as demoting the argument in A function so radically that it is no longer expressed in the clause (or is obligatorily expressed only via verbal affixation). In other words, the default Algonquian passive is agentless and possibly promotional. (Dryer 1997 considers the question of promotion irresolvable and ultimately uninteresting; cf. Dahlstrom 1986: Ch. 3 for an early formulation of the tests applied to determine subject status of the P argument.)

A further widespread commonality between Algonquian passives is morphological. Typically, with TA verbs, SAP passives are formally similar to transitive inverse forms, whereas 3rd-person passives are formally close to transitive direct forms. The following examples from Plains Cree illustrate some of the forms involved (from the independent order) ${ }^{9}$

\begin{tabular}{|c|c|c|}
\hline \multicolumn{3}{|l|}{ Plains Cree (Dahlstrom 1986: 68f) } \\
\hline a. Ni-sêkih-ikawi-n. & vs. & Ni-sêkih-ikw-w. \\
\hline 1-frighten.TA-PASS-SG.SAP & & 1-frighten.TA-INV-3 \\
\hline $\begin{array}{l}\text { 'I am frightened.' } \\
\text { (passive, } 1 \text { st person) }\end{array}$ & & $\begin{array}{l}\text { 'S/he (PROx) frightens me.' } \\
\text { (inverse, } 3 \rightarrow 1 \text { ) }\end{array}$ \\
\hline 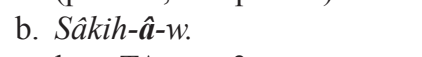 & vs. & Sâkih- $\hat{\boldsymbol{e}}-w$ \\
\hline love.TA-DIR 1 & & love.TA-DIR $2-3$ \\
\hline $\begin{array}{l}\text { 'S/he (PROX) is loved.' } \\
\text { (passive, 3rd person) }\end{array}$ & & $\begin{array}{l}\text { 'S/he (PROX) loves here/him (OBV). } \\
\text { (direct, } 3 \rightarrow 3 \text { ) }\end{array}$ \\
\hline
\end{tabular}

The forms on the left in (7) are passives (sometimes called "indefinite actor" forms in Plains Cree studies), featuring the suffixes $-i k a w i$ and $-\hat{a}$, respectively. The forms on the right are transitive direct forms, which have the theme signs $-i k w$ and $-\hat{e}$ respectively. Note that the passives with a 1st/2nd-person P argument show a passive (or impersonal) marker while those with a 3rd-person $\mathrm{P}$ do not.

The exact historical relationship between 3rd-person passive and inverse in Algonquian is still unclear, but these two morphemes always appear to be related somehow: Innu has -ikau and -iku (Drapeau 2014: Ch. 8); Miami-Illinois has -ekoo and -ekw for the same forms in the independent order but has the $1 \mathrm{P}$ or $2 \mathrm{P}$ markers plus a dedicated marker -en in the conjunct order (Costa 2003: Ch. 5); Ojibwe has -igoo and -igw (Valentine 2001:Ch. 7); Blackfoot has -okoo(wa) (SG) -oti (PL) and -ok (Frantz 2009: Ch. 11-12). Table 1 below gives an overview of 3rd-person passives for both the independent and the conjunct orders:

${ }^{9}$ Roughly, independent-order forms take personal prefixes and suffixes and are used in main clauses, while conjunct-order forms take only personal suffixes and are used in subordinate clauses (as well as some main clauses). 
Table 1: SAP passive markers (TA verbs)

\begin{tabular}{|c|c|c|}
\hline & Independent & Conjunct \\
\hline Plains Cree & \multicolumn{2}{|c|}{$-i k a w i$} \\
\hline Innu & \multicolumn{2}{|c|}{-ikau } \\
\hline Miami-Illinois & -ekoo & $(\text { SAP P suffixes }+-e n)^{10}$ \\
\hline Ojibwe & \multicolumn{2}{|c|}{-igoo } \\
\hline & \multicolumn{2}{|c|}{$-o k o o(w a)(\mathrm{SG})$} \\
\hline DTackioot & \multicolumn{2}{|c|}{$-o t i(\mathrm{PL})$} \\
\hline
\end{tabular}

The direct theme signs of passive and active forms with TA verbs are more clearly related: the SAP passive morpheme typically corresponds to the marker used with direct $\mathrm{SAP} \rightarrow 3$ forms. In Plains Cree, $-\hat{a}$ ' DIRECT, $_{1}$ ' occurs not only with SAP passives and $\mathrm{SAP} \rightarrow 3$ forms in the independent order but also with direct $3 \rightarrow 3$ forms and direct PL.SAP $\rightarrow 3$ forms in the conjunct; ${ }^{11}-\hat{e}$ ' DIRECT $_{2}$ ' occurs only with direct $3 \rightarrow 3$ forms in the independent order (Dahlstrom 1986: 68f). Miami-Illinois has a slightly simpler distribution: $-a a$ occurs with SAP passives and direct $\mathrm{SAP} \rightarrow 3$ forms in the independent order, as well as with direct $3 \rightarrow 3$ forms in the conjunct, and -ee occurs only with $3 \rightarrow 3$ forms in the independent order (Costa 2003: Ch. 5). ${ }^{12}$ The 3rd-person passive markers are summarized in Table 2:

Table 2: 3rd-person passive markers (TA verbs) $)^{13}$

\begin{tabular}{l|c|c}
\hline & Independent & Conjunct \\
\hline Plains Cree & $-\hat{a}$ & $(-$ iht $)$ \\
\hline Innu & \multicolumn{2}{|c}{- akan } \\
\hline Miami-Illinois & $-a a$ & $(\varnothing$ plus $-e n)$ \\
\hline Ojibwe $^{14}$ & $-a a$ & $(-$ ind $)$ \\
\hline Blackfoot $^{-}$ & $-a a$ \\
\hline
\end{tabular}

10 The 1PL.EXCL form is anomalous in that instead of expected *-i-n-amink-i (1P-INDF.A-1PL-CNJ), the actual affix string is - $i$-amink- $i$; note that the 1PL.EXCL suffix -amink occurs only in this particular form.

11 In the conjunct order, there is a dedicated morpheme -iht for SAP passives (its Ojibwe cognate -ind has the same function and distribution), and SG.SAP $\rightarrow 3$ forms take a zero allomorph of the direct morpheme.

12 The zero allomorph occurs in the conjunct on 3rd-person passives and on all direct SAP $\rightarrow 3$ forms.

13 The forms in parentheses represent portmanteaus that do not compare directly with the theme signs discussed here but are given for the sake of completeness.

${ }^{14}$ Even though the inflectional and derivational morphology of Ojibwe is similar to what is found in Plains Cree in many respects, it is in order to mention the "generalized/unspecified actor" forms in the former language. These are AI stems derived from other AIs (or, to some extent, TIs; in such cases, TIs morphologically and syntactically retain their inanimate $\mathrm{P}$ arguments) and simply take a dedicated argument marker $-m$ or some of its allomorphs (Valentine 2001: 689f). 
One of the noteworthy features of Algonquian passives is their heterogeneity with respect to the allomorphy they display (which suggests recent origin of some of these forms or their functions). Table 1 above already showed the Blackfoot SAP passive markers with TA verbs, which distinguish between singular and plural subjects; examples follow:

(8) Blackfoot (Frantz 2009: 61)
a. Nit-iikákomimm-okoo(wa). / Kit-iikákomimm-okoo(wa).
1-love.TA-PASS
2-love.TA-PASS
'I am loved.'
'You (SG) are loved.'
b. Nit-ikákomimm-oti-hpinnaan(a).
1-love.TA-PASS-1 PL.EXCL
'We (EXCL) are loved.'
c. Kit-ikákomimm-oti-hpoaawa.
2-love.TA-PASS-2PL
'You (PL) are loved.'
d. Iikákomimm-oti-hpa.
love-PASS-1PL.INCL
'We (INCL) are loved.'

Singular SAP passive -okoo(wa) stands in opposition to its plural counterpart -ots (the latter of which clearly suggesting an etymology, or possibly an underlying form, -oti < (*)-ot-i; see Frantz 2009:62); moreover, the 1PL.INCL suffix -hpa does not occur elsewhere on bivalent verbs in the TA paradigms, but it regularly occurs as subject marker in the AI and TI paradigms. The Blackfoot passive morphemes (and the direct and inverse markers) are summarized in Table 3:

Table 3: Selected TA suffixes in Blackfoot

\begin{tabular}{c|c|c|c}
\hline & Independent & Conjunctive & Subjunctive \\
\hline INV & $-o k$ & $-y i$ & - oti \\
\hline $1 \rightarrow 2$ & $-o o$ & $-o o$ & $-\varnothing$ \\
$2 \rightarrow 1$ & $-o k i$ & $-o k i$ & $-o k i$ \\
\hline PASS SG.SAP & $-o k o o(w a)$ & $-o k o o$ & $-o k o$ \\
PASS PL.SAP & $-o t i$ & $-o t i$ & $-o k o$ \\
PASS 3 & $-a a$ & $-a a$ & $-a a$ \\
\hline
\end{tabular}

Rather than a number- or a person-based allomorphy, Arapaho passives show a simple opposition between imperfective ( $-i$ for both AIs and IIs) and perfective passive markers (-eihi for AIs and -eihiinoo for IIs); examples follow:

Arapaho (Cowell \& Moss 2008: 152-153)
a. Bii'owuuni-' $i$
nii-cenen-i-3i'
IC.be.springtime.II-3SG.ITER
HAB-take.down.TA-AI:PASS -3 PL
nii'eihiisoon-o'.
'Eaglets are taken down [from their nests] in the springtime.'
eaglet-PL 
b. Ceecéecó'oh-éíhi-noo.

bless.ceremonially.TA-AI:PASS $-1 \mathrm{SG}$

'I have been ceremonially blessed.'

c. Ceecéecó 'oh-éíhiinóó-'.

bless.ceremonially.TA-II:PASS $-3 \mathrm{SG}$

'It (INAN) has been ceremonially blessed.'

While the imperfective passive does not allow the expression of the A argument in the clause, the perfective passive does. The corresponding NP is the only overt NP in the clause and is unmarked:

(10) Arapaho (Cowell \& Moss 2008: 155)

Koo'oe-notiton-eihi-3i' inee ihcebe' nii'eihiih-o'.

carefully-ask.TA-AI:PASS 2 -3PL that above.LOC eagle-PL

'They were asked [what they wanted] very meticulously by the eagles up above.'

Especially noteworthy is what Cowell \& Moss call a "middle voice construction" that does also allow the expression of the A argument $;{ }^{15}$ unlike the agentless passive markers, the AI final -ee does not distinguish aspect:

(11) Arapaho (Cowell \& Moss 2008: 155, 141)
a. Nestoow-ee-noo nuhu' nii'eihiih-o'.
warn.TA-AI:MID-1SG this eagle-PL
'I have been warned [about something] by the eagles.'
b. O3i'eew-ee-noo.
IC.ask.to.do.TA-AI:MID-1SG
'I have been asked to do something.'

The marker -ee occurs primarily (i.e. as the only or first final) with body-part and clothing-item expressions (e.g. tew-oon-ee- [break-leg-AI:MID-] 'have a broken leg', ciit-o'ohn-ii- [get.into-shoe-AI:MID-] 'put on shoes'). Secondarily (i.e. as the second final after a TA final, as in (11) above), however, it seems to be semantically nonspecific and quite productive.

The Arapaho markers discussed above are summarized in Table 4:

Table 4: Passive markers in Arapaho

\begin{tabular}{c|c|c|c}
\hline \multicolumn{3}{|c|}{ "passives" } & "middle" \\
\hline $\mathrm{IPFV}$ & $\mathrm{AFV}$ & $\mathrm{AI}$ \\
\hline $\mathrm{AI} / \mathrm{II}$ & AI & -eihinoo & -ee \\
\hline$-i$ & $-e i h i$ & & \\
\hline
\end{tabular}

15 Such clauses, particularly in the perfective aspect, appear to invariably have at most one explicit NP, viz. the one corresponding to the A argument. (In the imperfective aspect, by contrast, mention of the A argument seems to be extremely rare.) In elicitation, such NPs tend to occur in the obviative, but they occur rather as proximates in narrative texts. See Cowell \& Moss (2008: 154f) for more details. 
Innu passives show an interesting allomorphy unrelated to the oppositions mentioned for Blackfoot and Arapaho. Not only is there a person-based allomorphy that distinguishes SAP from 3rd-person passives for TA verbs; different verb stems take different allomorphs as well. Roughly, there are several kinds of AI stems, some of which (called $\mathrm{AI}^{\mathrm{TD} 1}$ here) pattern together with $\mathrm{TI}$ stems regarding passive morphology while the others $\left(\mathrm{AI}^{\mathrm{TD} 2-3}\right)$ pattern together with default AI stems. (Refer to the passages on Innu in Section 4 for the details.) This is summarized in Table 5:

Table 5: Passive markers in Innu

\begin{tabular}{ll|c|c}
\hline & SAP & 3rd person \\
\hline $\mathrm{TA} \quad$ (e.g. uap-am- 'see') & $-i k a u$ & -akan \\
\hline $\mathrm{TI} \quad$ (e.g. uap-ata- 'see') & - & -kan \\
\hline $\mathrm{AI}^{\mathrm{TD} 1} \quad$ (e.g. aia- 'buy') & & \\
\hline $\mathrm{AI}^{\mathrm{TD} 2}$ (e.g. tshimuti- 'steal') & - & -nanu \\
\cline { 1 - 2 } $\mathrm{AI}^{\mathrm{TD} 3} \quad$ (e.g. tshishi-patua- 'carry running') & & \\
\hline $\mathrm{AI} \quad$ (e.g. uashkamishi- 'be clean') & & \\
\hline
\end{tabular}

Lastly, note that the nanu-"passive" of default AI stems is actually an II impersonal form (e.g. atusse-nanu [work.AI-PASs] 'people/they work'). The nanu-form of $\mathrm{AI}^{\mathrm{TD} 2-3}$ stems, by contrast, are not impersonals but true passives; the animacy of their subject depends on whether they allow animate P arguments or not (see Section 4).

\section{Algonquian antipassives}

A restrictive definition of antipassivization (e.g. the one found in Dixon 1994: 16) requires a particular, crosslinguistically rather rare, pattern of grammatical relations to operate in languages that have such constructions. The canonical antipassive is a strict mirror image of the passive regarding both argument-related operations involved (and is therefore seen as semitransitive as well): it is both promotional (the A attains subject status) and demotional (the P loses subject status and is demoted to adjuncthood). To the best of my knowledge, this is not found in any Algonquian language.

The broader definition of antipassivization currently in fashion (e.g. Polinsky 2013; Janic 2016) omits the promotional part and has as necessary condition only the demotion of the argument in $\mathrm{P}$ function when compared to the active/basic construction. Such constructions are found in Algonquian languages, but they have not been studied in detail yet, at least from an Algonquian comparative perspective - let alone from a broader crosslinguistic perspective. Some descriptive studies mention them; here I briefly review Bloomfield (1962) for Menominee, Valentine (2001) for Ojibwe, and Goddard (1990) for Meskwaki/Fox, and I quote from Drapeau (2014) on Innu in a bit more detail. 
Bloomfield's description of Menominee discusses a special class of AI verbs he labels "verbs of indefinite action" (1962: 278). TA stems ending in Vw take the final -ki/-ko; he mentions some morphophonemic irregularities and the finals $-\varepsilon \cdot s e$ and $-E w \varepsilon \cdot$, as well as $-a \cdot k \varepsilon \cdot$ (which is otherwise found with indefinite action verbs derived from TI stems), which are found with a reduced number of verbs. TI stems corresponding to the Vk-final TAs take $-a \cdot k \cdot \cdot$ while other TI stems usually take $-k \varepsilon \cdot$, but there are irregularities and exceptions as well. Essentially, then, Bloomfield sees these as derived verbs that refer to actions on someone or something unspecified or on persons or things in general.

Valentine (2001) mentions three kinds of "detransitive" finals (pp. 403f) found in Ojibwe "antipassives" (pp. 693-694):

(12) Ojibwe (Valentine 2001: 403f)
a. -(i)ge
"actor focus detransitive" (variety of TA/TI stems)
b. -(i)we
"actor focus detransitive, human goal" (TA stems in $h / N / S / n *$ )
c. -aaso
"actor focus detransitive" (small number of TI stems)

They show some variation and specificity but share the property that the $\mathrm{P}$ argument is a primary object with the basic TI/TA verb but is suppressed, i.e. absent from the clause, with the derived verb. The A argument retains its subject status. The first of these occurs in AI naadmaa(w)-ge- 'help (people)' (cf. TA naadmaw- 'help'), while the second tends to occur with TA stems ending in particular segments, e.g. AI baabiih-we- 'wait (for people)' (cf. TA baabiih- 'wait for'). The final -aaso occurs on a small number of TI verbs but shows a different formal behavior: the TI direct theme sign (-am or $-o o$ ) is absent from the AI form, e.g. in gind-aaso- 'count, read' (cf. TI gind-am- 'count')

Goddard (1990) mentions AI stems that are derived from either TI or TA stems in Meskwaki by means of an operation that suppresses the $\mathrm{P}$ argument. Note the similarity to Menominee $-k \varepsilon \cdot$ and to Ojibwe $-(i) g e$ :

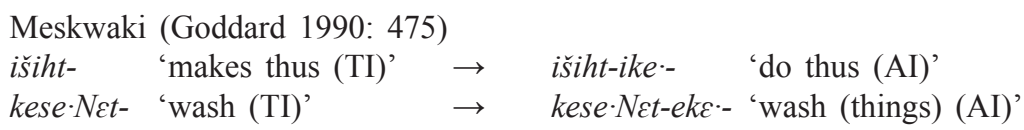

(14) Meskwaki (Goddard 1990: 475)
a. kano $\cdot N-$
'speak to (TA)'
$\rightarrow \quad k a n o \cdot N-k y e \cdot-\quad$ 'speak (AI)'
b. wa.pam-
'look at (TA)'
$\rightarrow \quad$ wa.pam-ke-
c. no.taw-
'hear (TA)'
$\rightarrow$
no.taw-eke-
'look (AI)'
d. $e N-$
'say thus to (TA)' $\rightarrow$
eN-iwe-
'hear (AI)'
'say thus (AI)'

Lastly, Drapeau (2014) mentions two suffixes found in Innu that form P-suppressing or absolute antipassives. They are in complementary distribution; the ue-antipassive is used only with causativized bases:

Innu (Drapeau 2014: 240)
a. Nipa-i-e-u.
die.AI-TA:CAUS-DIR-3
'S/he kills him/her.' 

b. Eukuan aueshish nipa-i-ue-t. it.is animal die.AI-TA:CAUS-AI:ANTIP-3
'It is an animal that kills.'

The tshe-antipassive, by contrast, can take any of three kinds of bivalent bases (16), viz. TA stems (a-b) ${ }^{16}$ TI stems (c-d), and $\mathrm{AI}^{\mathrm{TD} 1}$ stems (e-f):

(16) Innu (Drapeau 2014: 238-239)
a. Pieǹ nashpitutu-e-u iǹnutshimau-a.
P. imitate.voice.TA-DIR-3 chief-OBV
'Pierre imitates the chief's voice.'
b. Pieǹ nashpituta-tshe-u.
P. imitate.voice.TA-AI:ANTIP-3
'Pierre imitates voices / makes impersonations.'
c. Pù̀ ashtu-ei-m- ${ }^{u}$ ishkutè̀u.
P. put.off-TI-DIR.3-3 fire
'Paul put off the fire.'
d. Pù̀ ashtu-ei-tshe-u.
P. put.off-TI-AI:ANTIP-3
'Paul puts off (things).'
e. Pù̀ apu tshekuaǹ-nu nipa-ta-t.
P. NEG something-OBV die.AI-AI ${ }^{\mathrm{TD} 1}-3$
'Paul did not kill anything.'
f. Pù̀ apu nipa-ta-tshe-t.
P. NEG die.AI- $\mathrm{AI}^{\mathrm{TD} 1}$-AI:ANTIP-3
'Paul has not killed (i.e. is empty-handed),'

I have not been able to find suppressing/absolute antipassives in Blackfoot, nor have $\mathrm{I}$ been able to find Algonquian antipassives that demote the $\mathrm{P}$ argument from primary object to adjunct. More research is needed here.

\section{Algonquian transitivity discord constructions}

Even though Algonquian languages differ in numerous and important ways from Oceanic languages, there is one particular construction in the former that shows remarkable formal and functional parallels to the TDCs described by Benton (1967), Sugita (1973) and Margetts (2008) for the latter. The following Blackfoot equivalents to English 'borrow' illustrate the opposition between a morphologically monovalent verb (AI waahkomát-aa-) that can nonetheless take an object (albeit a secondary, rather than a direct or primary, object; more on this below) and two kinds of morphologically and syntactically bivalent verbs (TI waahkomá t-atoo- and TA waahkomát-at- for inanimate and animate primary objects, respectively):

${ }^{16}$ With some TA verbs that denote specific physical effect on humans or animals (e.g. make thirsty, block one's way), the subject of the tshe-antipassive can be animate or inanimate; see Drapeau (2014: 239-240) for examples. 
(17) Blackfoot (Russell et al. 2012)

a. Ø-waahkomá't-aa-wa isspiksísoka'siM-i.
3-borrow-AI-3SG.PROX
'S/he borrowed a coat.'

b. Ø-waahkomá't-atoo-m-wa ni-asóka’siM-yi.

3-borrow-TI-INAN.TH-3SG.PROX 1-jacket-INAN.SG

'S/he borrowed my jacket.'

c. Ø-waahkomá 't-at-ii-wa n-otá 's-yi.

3-borrow-TA-DIR-3sG.PROX 1-horse-OBV

'S/he borrowed my horse.'

The AI verb form of (a), waahkomátaawa, can also be used without specifying the $\mathrm{P}$ argument, in which case it simply means 's/he borrowed (something)' or 's/he borrowed (whatever is adequate according to the context)'. There is, then, a systematic potential mismatch between the morphological valency of the predicate (one) and the syntactic valency of the clause (one or two); semantic valency is arguably always two with such verbs. As far as transitivity is concerned, Blackfoot invariably uses such verb forms, and such clauses, for states of affairs that are less than fully transitive; the typical triggering factor is the $\mathrm{P}$ argument being nonspecific.

Algonquian studies have called the TDC in (a) and/or verbs that head them "pseudo-transitive" (Bloomfield 1957: 33-34 for Eastern Ojibwe), "intransitive verbs with an implied object" (Bloomfield 1962: 46-47 for Menominee), "semi-transitive" (Cowell \& Moss 2008: 125 for Arapaho), and "paratranstive" (Frantz 2009: 41 for Blackfoot). Some descriptions postulate a separate stem class for such verbs, alongside the traditional TI and TA classes, usually called AIO or AI+O (Rhodes 1985; Dahlstrom 2009, 2013).

Drapeau's description of Innu is a case in point (2014: 140f). The four default Algonquian classes are robust in the language, but there are three additional stem types following Drapeau, I will treat them as "atypical" AI stems here - that can be postulated, all of which show transitivity discord. The first, and most numerous, class (AI $\left.{ }^{\mathrm{TD} 1}\right)$ consists of verbs that take AI inflections in the active voice but -kan as passive marker (i.e. the same as TIs). They occur with an inanimate object and are paired to corresponding TA verbs (e.g. AI ${ }^{\mathrm{TD} 1}$ aia- vs. TA aia-u- 'buy', AI ${ }^{\mathrm{TD} 1}$ uni-ta- vs. TA uni- 'lose'), usually showing a - $t a$ final; most of Drapeau's examples seem to denote some kind of physical manipulation. ${ }^{17}$ The other two classes are comparatively less numerous. An AI ${ }^{\mathrm{TD} 2}$ class consists of verbs that take AI inflections in the active and passive voices and can take an object, even though they are more frequently used without an object in the clause. Some have a corresponding TA verb (e.g. AI ${ }^{\mathrm{TD} 2}$ amatshue-tuate- vs. TA amatshue-tutam'climb a slope with (a load) on one's back'), in which case they take an inanimate object. Others do not have a paired TA verb, in which case they are insensitive to the animacy of the object but cannot occur with SAP Ps (e.g. AI ${ }^{\mathrm{TD} 2}$ tshimuti- 'steal'). ${ }^{18}$ Lastly, the $\mathrm{AI}^{\mathrm{TD} 3}$ class consists of verbs that take $\mathrm{AI}$ inflections in the active and passive voices and are normally used with an object. Some have paired TA verbs, in which case they take

17 Drapeau (2014: 142-143) calls them VAIT and argues against treating them as a subclass of TI stems.

18 Drapeau (2014: 143-145) calls these stems "VAI ambitransitifs." 
an inanimate object; others do not have a paired TA verb, in which case they are insensitive to the animacy of the object but cannot occur with SAP Ps. Most verbs belonging to this class seem to take either the primary final -patua (e.g. $\mathrm{AI}^{\mathrm{TD} 3}$ tshishi-patua- 'start off running carrying (something / somebody)' or the secondary final uatshe; in the latter case, the derived form is actually an instrumental secondary applicative, in that it takes a secondary, instead of a primary, object (i.e. it is inflected like an AI stem). ${ }^{19}$

Similarly, Valentine (2001: 218) distinguishes three subclasses of AI stems for Ojibwe: (i) default AIs (the most numerous class); (ii) an $\mathrm{AI}^{\mathrm{TD} 1}$ subclass with $\mathrm{AI}$ inflection but with "optional objects" (which can be either animate or inanimate if the semantics is appropriate); ${ }^{20}$ and (iii) an $\mathrm{AI}^{\mathrm{TD} 2}$ subclass with $\mathrm{AI}$ inflection, clausal complements in some cases (e.g. $\mathrm{AI}^{\mathrm{TD} 2}$ debwetam- 'believe'), and a TI theme sign -am. ${ }^{21}$ The core of the latter subclass revolves around experiencer predicates ("states of the main, or mental processes"). The list of most common $\mathrm{AI}^{\mathrm{TD} 1}$ verbs in Valentine (2001: 242) includes 50 verbs of quite varied semantics, but many seem to have either -(i)ge or -we finals, which are (homonymous with) the antipassive markers mentioned in Section 3 above - more research is needed here.

It is important to say that the phenomenon of discord is not limited to AI verbs. In Innu, there are two kinds of TI stems as well, viz. typical (those actually taking objects) and atypical (those inflecting like TIs but not occurring with objects of any kind in the clause). Their semantic core seems to consist of experiencer verbs on the one hand ('be happy', 'reflect', 'be bored') and motion verbs that express displacement by means of boat or foot on the other; they do not seem to be numerous. ${ }^{22}$ Interestingly enough, the two subclasses of TI verbs have different causative allomorphs; both default AI stems and non-default subclass of TI stems (viz. $\mathrm{TI}^{\mathrm{TD}}$ stems) take the suffix $-i$ when causativized; default TI stems take uni instead:

(18) Innu (Drapeau 2014: 222-223)
a. Kakashtekupeshkueu
nikamu-i-e-u
auass-a.
nun sing.AI-TA:CAUS-DIR-3
child-oBV
'The nun makes the child(ren) sing.'
b. Natukuǹnish apasheǹitam-i-e-u nit-akushiunnim-inan-a. physician come.to.TI ${ }^{\mathrm{TD}}$-DIR-3 1-sick-1PL-OBV
'The physician makes our sick person come to.'
c. Kakashtekupeshkueu kutam-uǹi-e-u swallow.TI-TA:CAUS-DIR-3 child-OBV nun natukuǹ-ǹu. 'The nun makes the child swallow a medicine.' medicine-OBV

19 Drapeau (2014: 145-146) calls these stems "VAI+O."

${ }^{20}$ Valentine (2001: 218) calls these "VAIO."

${ }^{21}$ Valentine (2001: 218) calls these "PS-VAl" / "pseudo-intransitive" and actually says that the am on the stem of these verbs is "a stem element that resembles the theme sign /-am/ of some transitive inanimate (VTI) verbs."

${ }^{22}$ Drapeau (2014: 141-142) calls these "VTI sans objet." 
Bloomfield finds an analogous situation in Menominee and Ojibwe: there are morphologically (quasi-)AI verbs that can take objects (either animate or inanimate) and there are morphologically (quasi-)TI verbs that do not take objects. For Menominee, he says that atypical AI verbs take "implied objects," and atypical TI verbs have "purely formal objects" (1962: 46-47). For Ojibwe, he uses a somewhat different terminology for what is essentially the same phenomenon: atypical AI verbs are "pseudo-transitive" and take "pseudo-objects," and atypical TI verbs are "pseudo-intransitive" and take "purely formal objects" (1957: 33-34).

Lastly, it seems that all Algonquian languages distinguish primary from secondary objects. ${ }^{23}$ In other words, and abstracting from the many language-specific details (like the allomorphy of passive and causative markers in Innu), there are two general cases of transitivity discord in the languages surveyed here: (i) morphologically monovalent verbs that are syntactically bivalent and (ii) morphologically bivalent verbs that are syntactically monovalent. Both can be said to be semitransitive, possibly with the latter closer to the intransitive pole than the former (if semantics and syntax are seen as more central indicators than merely verb morphology). This is summarized in Table 6:

Table 6: Transitivity discord in Algonquian

\begin{tabular}{l|c|c|c}
\hline & Derivation & Inflection & Syntax \\
\hline Transitive $^{24}$ & Default TA/TI & Bipersonal & $\mathrm{A}=$ SBJ, $\mathrm{P}=$ POBJ \\
\hline \multirow{2}{*}{ Semitransitive: $\mathrm{TD}$} & $\mathrm{AI}^{\mathrm{TD}}$ & Monopersonal & $\mathrm{A}=\mathrm{SBJ}, \mathrm{P}=$ SOBJ \\
& $\mathrm{TI}^{\mathrm{TD}}$ & Bipersonal & $\mathrm{S}=\mathrm{SBJ}$ \\
\hline Intransitive & Default $\mathrm{AI} / \mathrm{II}$ & Monopersonal & $\mathrm{S}=\mathrm{SBJ}$ \\
\hline
\end{tabular}

\section{Concluding remarks}

The synchronic picture that emerges from the preceding three sections is an interesting one. On a concrete micro level, there is much variation as to the voice markers and their allomorphy, but also as to their lexical conditioning and applicability - details that are likely to interest primarily the language specialist or the Algonquianist. On an abstract macro level, however, typologists can see the semitransitive zone as a rather densely populated area; in addition to the reflexives and reciprocals, as well as to the nominal incorporation construction (all of which I have not addressed in this article), there is

${ }^{23}$ Bloomfield's "pseudo-objects" seem to be, according to all evidence available to me, secondary objects. See Russell et al. (2012) for Blackfoot, Dahlstrom (2009) for Meskwaki, and Dahlstrom (2013) for Central Algonquian languages in general. I understand Drapeau's (2014) description of the Innu data in the same way.

${ }^{24}$ I am glossing over two important details here: (1) the existence of trivalent TAs like 'give', which have $\mathrm{A}=$ SBJ, $\mathrm{T}=$ SOBJ, and $\mathrm{G}=$ POBJ, and (2) the possibility of a different syntax for direct and inverse clauses (e.g. $\mathrm{A}=$ POBJ, $\mathrm{P}=$ SBJ for inverses). 
a remarkable morphosyntactic division of labor between different kinds of constructions between the transitive and the intransitive poles.

It is well-known that there are two kinds of transitive, i.e. syntactically bivalent, clauses in Algonquian languages, viz. direct and inverse (however they are to be understood syntactically; see Zúñiga 2006 for the argument that direct clauses and inverse clauses may have a different syntax, at least in some (non-Algonquian) languages). Depending on topicality, animacy, and person, speakers choose between those two constructions in order to portray high-transitivity states of affairs.

States of affairs of diminished transitivity appear to have a host of specialized form-function pairs. First, if the argument in A function is unknown or irrelevant (or is better left out for whatever reasons), passive constructions are chosen. These are A-suppressing and possibly P-promotional, and they are customarily treated as inflectional in Algonquian studies, due to the inflectional similarity passive verb forms show to active direct and inverse forms. (Ojibwe has an impersonal construction as well, which requires more language-internal and comparative research. Arapaho, on the other hand, has a non-suppressing passive that represents something of an anomaly and needs more indepth research as well.) Second, if the argument in P function is unknown, irrelevant or generic, antipassive constructions are chosen. These are P-suppressing, and they are customarily treated as derivational in Algonquian studies; they appear to show a high degree of lexicalization and are quite unlike antipassives in many other languages, which are morphologically simple and highly productive. Third, there are transitivity discord constructions, which occur according to intricate patterns; whenever verbs that take the TDC alternate with default transitive verbs, they seem to be chosen when the argument in $\mathrm{P}$ function is not necessarily generic but at least nonspecific (as in Blackfoot); whenever they do not alternate freely with default transitive verbs, or do so only in a limited fashion, they seem to prefer predicates with low-affectedness Ps (as in Innu and Ojibwe), but the verbs in this situation go beyond experiencer verbs and include verbs of transaction/ transfer and verbs of physical manipulation as well. This is summarized in Table 7.

Table 7: Selected semitransitive constructions in Algonquian

\begin{tabular}{l|c|c|c}
\hline & Derivation & Syntax & Transitivity \\
\hline Passive & $\mathrm{AI}$ & $\mathrm{P}=\mathrm{SBJ}$, A suppressed & Backgrounded A \\
Antipassive & $\mathrm{AI}$ & $\mathrm{A}=\mathrm{SBJ}, \mathrm{P}$ suppressed & Backgrounded (unknown/generic) $\mathrm{P}$ \\
TDC & $\mathrm{AI}^{\mathrm{TD}}$ & $\mathrm{A}=\mathrm{SBJ}, \mathrm{P}=$ SOBJ & (Backgrounded (nonspecific) $\mathrm{P}$ ) \\
\hline
\end{tabular}

In the terms outlined in Section 1.1, these constructions occupy a semantic space that is intermediate between the expression of low and high transitivity. Algonquian intransitive clauses have only one semantic argument, which corresponds to the only morphological and only syntactic argument. Algonquian transitive clauses, by contrast, have two semantic arguments, which correspond to the two morphological and the two syntactic arguments. Antipassives seem to be close to the intransitive pole, with two semantic arguments but only one morphological and syntactic argument. Passives are heterogene- 
ous both across and within Algonquian languages. Remember from Section 2 that they are suppressing, like antipassives, but not clearly promotional and particularly different, at least with respect to their morphology, in the cases of 1 st $/ 2$ nd- and 3rd-person $\mathrm{P}$ arguments. TDCs are perhaps closest to the transitive pole in that the two semantic arguments are still instantiated in the syntax of the clause (but not in the morphology of the predicate), and in that nonspecific $\mathrm{P}$ arguments are nonetheless more individuated than unknown/generic ones.

Even though Algonquian studies have addressed so-called passives, more research is needed on the specifics of Algonquian impersonals and (quasi-)middles, but especially on antipassives, which are not fully understood yet. More research will also, hopefully, deepen our understanding of the Algonquian TDCs and the role they play in the grammar of these languages - among other things, in the spirit of Margetts (2008), the division of labor vis-à-vis nominal-incorporation constructions.

\title{
Acknowledgements
}

I am indebted to two anonymous reviewers for their valuable comments on a previous version of this article. The usual disclaimers apply.

\begin{abstract}
Abbreviations
A - agent-like argument of bivalent/trivalent predicates; AI - animate intransitive; ANTIP - antipassive; APPL - applicative; CAUS - causative; DIR - direct; EXCL - exclusive; G - goal-like argument of trivalent predicates; HAB - habitual; IC - initial change; II - inanimate intransitive; INAN - inanimate; INCL - inclusive; INCOMPL - incompletive; INV - inverse; ITER - iterative; MID - middle; NSPEC - nonspecific; OBV - obviative; $\mathrm{P}$ - patient-like argument of bivalent predicates; PASS - antipassive; PL - plural; POBJ - primary object; PROX - proximate; REAL - realis; RECIP - reciprocal; REFL - reflexive; S - single argument of monovalent predicates; SAP - speech act participant; SBJ - subject; SG - singular; SOBJ - secondary object; $\mathrm{T}$ - theme-like argument of trivalent predicates; TA - transitive animate; TD - transitivity discord; TDC - transitivity discord construction; TH theme; THC - thematic consonant; TI - transitive inanimate; V - verb.
\end{abstract}

\section{References}

Aissen, Judith. 1997. On the syntax of obviation. Language 73(4). 705-750.

Benton, Richard. 1967. An introduction to the Trukese language for speakers of English. Honolulu: Pacific and Asian Linguistics Institute, University of Hawaii.

Bloomfield, Leonard. 1946. Algonquian. In Hoijer, Harry et al. (eds.), Linguistic structures of Native America, 85-129. New York: Viking Fund Publications in Anthropology.

Bloomfield, Leonard. 1957. Eastern Ojibwa: grammatical sketch, texts and word list. Ann Arbor: The University of Michigan Press.

Bloomfield, Leonard. 1962. The Menomini language. New Haven: Yale University Press.

Costa, David. 2003. The Miami-Illinois language. Lincoln: University of Nebraska Press. 
Cowell, Andrew \& Moss, Sr., Alonzo. 2008. The Arapaho language. Boulder: The University Press of Colorado.

Dahlstrom, Amy. 1986. Plains Cree morphosyntax. Berkeley: University of California. (Doctoral dissertation.)

Dahlstrom, Amy. 2009. OBJ $_{\Theta}$ without OBJ: a typology of Meskwaki objects. In Butt, Miriam \& King, Tracy H. (eds.), Proceedings of the LFG09 Conference, 222-239. Stanford: CSLI Publications.

Dahlstrom, Amy. 2013. Argument structure of quirky Algonquian verbs. In King, Tracy H. \& de Paiva, Valeria (eds.), From Quirky Case to representing space: papers in honor of Annie Zaenen, 61-71. Stanford: CSLI Publications.

Dixon, R. M. W. 1994. Ergativity. Cambridge: Cambridge University Press.

Drapeau, Lynn. 2014. Grammaire de la langue innue. Québec: Presses de l’Université du Québec.

Dryer, Matthew. 1997. Passive vs. indefinite actor construction in Plains Cree. In Pentland, David (ed.), Papers of the 26th Algonquian Conference, 54-79. Winnipeg: University of Manitoba.

Dryer, Matthew. 2007. Clause types. In Shopen, Timothy (ed.), Language typology and syntactic description, Vol. I: clause structure, 224-275. Cambridge: Cambridge University Press.

Frantz, Donald. 2009. Blackfoot grammar. 2nd edition. Toronto: Toronto University Press.

Goddard, Ives. 1990. Primary and secondary stem derivation in Algonquian. International Journal of American Linguistics 56(4). 449-483.

Heath, Jeffrey. 1999. A grammar of Koryaboro (Koroboro) Senni: The Songhay of Gao, Mali. Cologne: Rüdiger Köppe.

Hopper, Paul \& Thompson, Sandra. 1980. Transitivity in grammar and discourse. Language 56(2). 251-299.

Janic, Katarzyna. 2016. L'antipassif dans les langues accusatives. Brussels: Peter Lang.

Keen, Sandra. 1983. Yukulta. In Dixon, R. M. W. \& Blake, Barry (eds.), Handbook of Australian languages 3, 190-304. Amsterdam: John Benjamins.

Kemmer, Suzanne. 1993. The middle voice. Amsterdam: John Benjamins.

Kemmer, Suzanne. 1994. Middle voice, transitivity, and the elaboration of events. In Fox, Barbara \& Hopper, Paul (eds.), Voice: form and function, 179-230. Amsterdam: John Benjamins.

Kleinschmidt, Samuel Petrus. 1851. Grammatik der grönländischen Sprache, mit theilweisem einschluss des Labradordialects. Berlin: G. Reimer.

Lichtenberk, Frantisek. 1983. A grammar of Manam. Honolulu: The University of Hawai'i Press.

Margetts, Anna. 2008. Transitivity discord in some Oceanic languages. Oceanic Linguistics 47(1). 30-44.

Polinsky, Maria. 2013. Antipassive constructions. In Dryer, Matthew \& Haspelmath, Martin (eds.), The World Atlas of Language Structures online, Chapter 108. Leipzig: Max Planck Institute for Evolutionary Anthropology. (Available at http://wals.info/chapter/108, accessed on 2016-11-20.)

Prost, André. 1956. La langue soriay et ses dialectes. Dakar: IFAN.

Rhodes, Richard. 1985. Eastern Ojibwa-Chippewa-Ottawa dictionary. New York: Mouton.

Russell, Lena \& Genee, Inge \& Van Lier, Eva \& Zúñiga, Fernando. 2012. Referential hierarchies in three-participant constructions in Blackfoot: the effects of animacy, person, and specificity. Linguistic Discovery 10(3).

Sugita, Hiroshi. 1973. Semitransitive verbs and object incorporation in Micronesian languages. Oceanic Linguistics 12(1/2). 393-416.

Valentine, J. Randolph. 2001. Nishnaabemwin reference grammar. Toronto: University of Toronto Press.

Zúñiga, Fernando. 2006. Deixis and alignment: inverse systems in indigenous languages of the Americas. Amsterdam: John Benjamins. 